\title{
TIDAL WAVE REFLECTION FROM THE CLOSURE DAM IN THE GUADALQUIVIR ESTUARY (SW SPAIN)
}

\author{
Manuel Díez-Minguito ${ }^{1}$, Asunción Baquerizo ${ }^{1}$, Miguel Ortega-Sánchez ${ }^{1}$, Inmaculada Ruiz ${ }^{1}$, and Miguel. Á. Losada ${ }^{1}$
}

\begin{abstract}
Closure dams in estuaries and tidal areas have a strong impact on their hydrodynamics and morphology. Among other reasons, this impact can be due to tidal reflection. In the Guadalquivir estuary (SW Spain), data measured allowed to identify a partially standing motion along the upper third of the estuary. We estimate the frequencydependent complex reflection coefficients at the head dam, and analyze the effect of the combined action of the incident and reflected tidal waves on the residual currents. Erosion-deposition patterns induced by the tidal reflection were identified. The most energetic tidal constituent, the semidiurnal M2, favors sedimentation near the entrance of the Port of Seville, where the most intense dredging works take place. Finally, we briefly discuss the potential consequences of reflection on the turbidity spatial distribution.
\end{abstract}

Keywords: Guadalquivir estuary, tidal reflection, dam, reflection coefficient, mass transport, morphodynamics

\section{INTRODUCTION}

The Guadalquivir River estuary is located in the SW of the Iberian Peninsula, facing to the Gulf of Cádiz (see Figure 1). It extends as far as the Alcalá del Río dam, $110 \mathrm{~km}$ upstream from the sea at Sanlúcar de Barrameda. The estuary is relatively narrow and convergent. Tidally-averaged sections and widths show a mild decrease, with a convergence length of approximately 60 and $65 \mathrm{~km}$, respectively (Díez-Minguito et al., 2012a). The estuary falls in class Type-2a of the Hansen and Rattray classification system (Hansen and Rattray, 1965; Dyer,1973), which means that the estuary is well mixed and presents a baroclinic or gravitational circulation, more evident near the mouth. The alongchannel mean water depth is about $7 \mathrm{~m}$. This is maintained by periodic dredging works in order to allow ships to reach the Port of Seville, which is separated from the main channel by a lock. Tides are mesotidal and semidiurnal (Álvarez et al. 2001), being the most important constituent the M2 $\left(T_{M 2}=12.45\right.$ hours). The head dam at Alcalá del Río is the upstream boundary (Figure 1), i.e. the last monitoring point of the freshwater discharges and the upestuary propagation limit of the tides. The river discharges released by the Alcalá del Río dam are normally lower than $40 \mathrm{~m}^{3} / \mathrm{s}$ (Díez-Minguito et al., 2012a). The results presented here are obtained during those conditions.

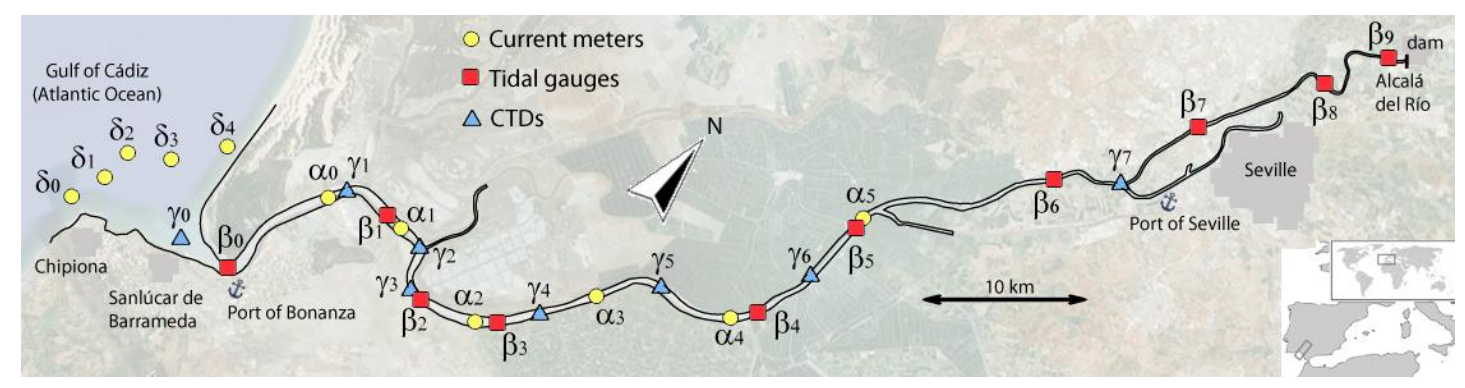

Figure 1. The Guadalquivir River estuary. The monitoring network installed along the main channel is composed of six current-meter profilers (yellow circles), ten tidal gauges (red squares) and eight environmental quality probes or CTDs (blue triangles). The network also includes five current-meters and a meteorological station (not shown) placed on the inner shelf. The background picture was adapted from Google Earth.

In 2008, a real-time remote monitoring network, operated by the Instituto de Ciencias Marinas de Andalucía (ICMAN-CSIC), was deployed all along the main course of the estuary and the inner continental shelf (Navarro et al., 2011). The ultimate purpose of the network was to assess the impact of possible human interventions and natural forcings in the morpho-hydrodynamics of the estuary. The stations were positioned along the estuary and river mouth and maintained during three years (2008-

\footnotetext{
${ }^{1}$ Environmental Fluid Dynamics Group, University of Granada, Interuniversity Research Institute of Earth System in Andalusia, E-18006, Granada, Spain
} 
2011). The map of the study site (Figure 1) also shows their locations. The elevation of the free water surface was recorded by an array of tidal gauges moored at various points between the estuary mouth and the head dam. This tidal gauges (denoted by $\beta$ 's and red squares in Figure 1) provide a level datum in mbar every $10 \mathrm{~min}$. The environmental quality stations (denoted by $\gamma$ 's and blue triangles in Figure 1) record conductivity and turbidity among other data, every 30 minutes. These stations take samples at four depths at one-meter intervals from the free water surface. Six $1 \mathrm{kHz}$ current meters (denoted by $\alpha$ 's and yellow circles in Figure 1) supply data regarding the along-channel current in the entire water column. They take measurements from the free water surface to the bottom, and provide one data set per meter every $15 \mathrm{~min}$, with an integration period of $2 \mathrm{~min}$. Additional details on the monitoring network can be found elsewhere (Navarro et al., 2011; Navarro et al., 2012; Díez-Minguito et al., 2012). The origin of the along-channel coordinate $x$ was established at the monitoring station $\gamma_{0}$, installed at the mouth of the estuary. The coordinate $x$ is positive upstream, following the axis of the main channel.
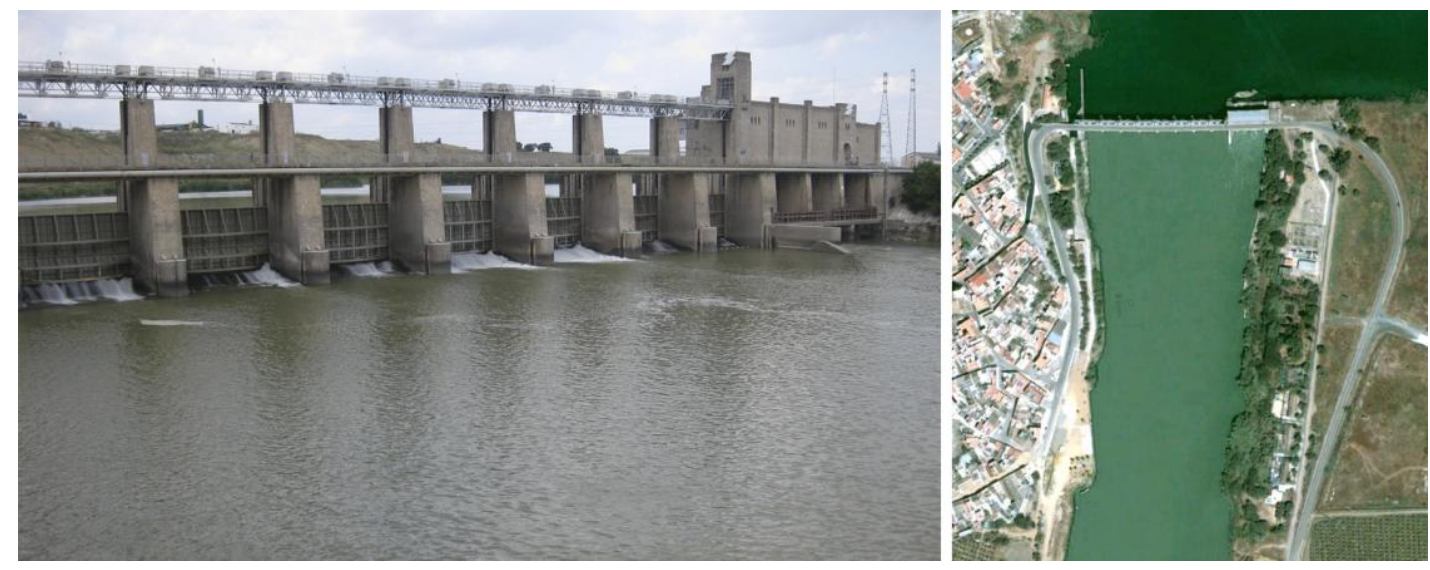

Figure 2. Alcalá del Río head dam. Left panel: picture taken in 05/28/2010 by the authors. Right panel: satellite view.

\section{SIGNS OF TIDAL REFLECTION ON THE HEAD DAM}

A preliminary analysis of data measured by the monitoring network revealed the occurrence of tidal reflection at the head dam (pictures shown in Figure 2). This is evidenced by the notable increase of the

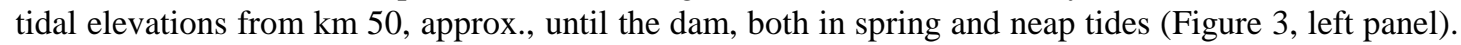
This behavior cannot be ascribed to bathymetric changes, since sections show a rather uniform, mild decay from the mouth to the dam. During spring tides (red squares), the amplitudes regain almost the same value that they had at the inner shelf. More significant is the increase during neap tides (blue circles) because of the friction dependence on the amplitude of the tidal flow (Wang and FernándezBermejo, 2010). During neap tides, elevations increase up to $60 \%$.
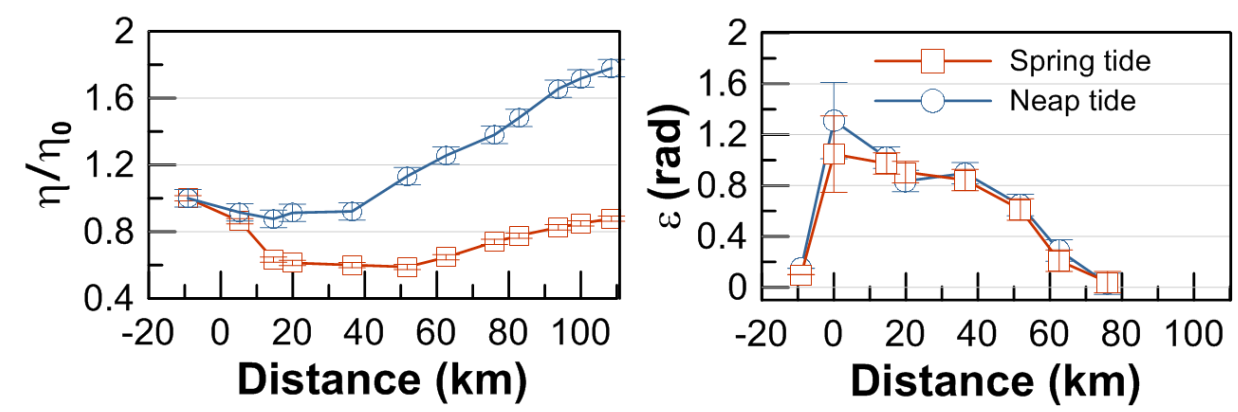

Figure 3. Left panel: longitudinal variation of the tidal amplitude both in spring and neap tides nondimensionalized by their respective values at the estuary mouth. The spring and neap tide amplitudes at the mouth are respectively, $316 \mathrm{~cm}$ and $97 \mathrm{~cm}$. Right panel: Phase lag between the high water slack and the high water in the estuary and inner shelf during spring tides as well as neap tides. 
Another sign of tidal reflection is observed in the tidal phases of the semidiurnal, diurnal, quarter diurnal, and fortnightly constituents. Figure 4 shows their phases, derived from a harmonic analysis of the water levels, as a function of the distance to the mouth. For all the harmonics analyzed the tidal phases become horizontal near the dam, which is an indication of a standing motion. This is more evident in the harmonics with the longer wavelengths (Prandle and Rahman, 1980). For instance, the M2 constituent phase (Figure 4, third panel) grows approx. linearly upestuary in the middle stretch of the estuary and its phase slope is observed to be zero only in the last $20 \mathrm{~km}$. On the other hand, the MSf phase changes at the estuary mouth (Figure 4, first panel), but little variation was perceived with the distance. For quarter-diurnals large phase differences are observed (Figure 4, rightmost panel), and high amplification of elevations and one nodal position near $\mathrm{km} 60$ (not shown). Zero slopes are also observed close to the dam for these overtides. Analytical results obtained from the solutions of the linearized one-dimensional shallow-water wave equations also exhibit this behavior (Prandle and Rahman, 1980). Figure 4 shows the results for the MSf, K1, M2, and M4 constituents in the Guadalquivir estuary. The theory assumes a) that the estuarine width and depth spatial variation may be approximated by power laws with exponents $n=0.729$ and $m=0.0609$, respectively; and b) that the tidal limit extends $10 \mathrm{~km}$ upstream without the closure dam. The later assumption was made in accordance with historical descriptions of the estuary before the dam construction. The linearized friction coefficients which best fit our data are $s_{M S f}=0.88, s_{K 1}=0.45, s_{M 2}=0.88$, and $s_{M 4}=1.77 \mathrm{~h}^{-1}$. The theoretical results are in good agreement with the observed phases. The friction coefficient $s_{M 4}$ is, in relative terms, large due to the internal generation of overtides by non-linear processes within the estuary.
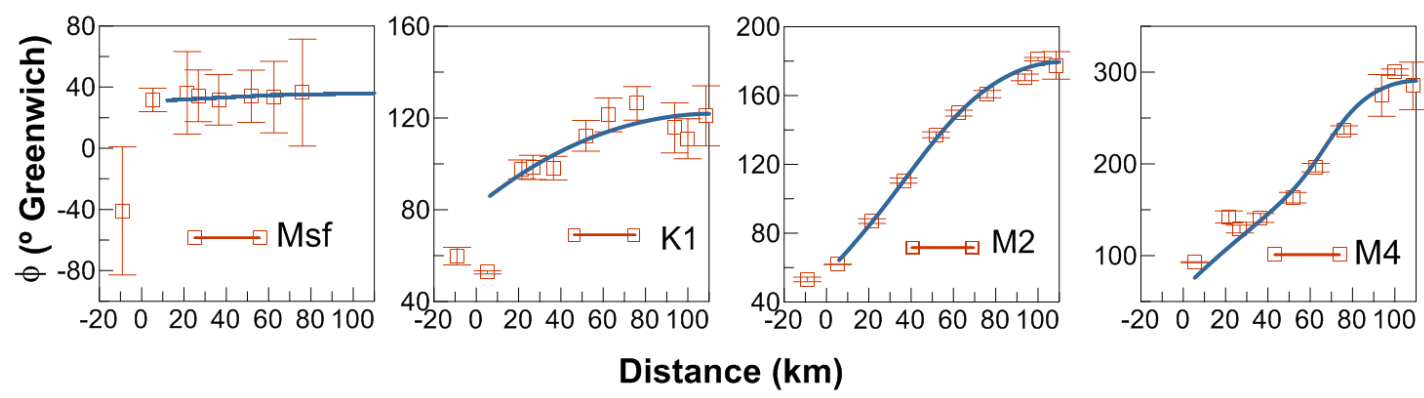

Distance $(\mathbf{k m})$

Figure 4. Tidal phases with the $95 \%$ confidence interval estimates derived from a harmonic analysis of the water levels (red squares). The corresponding tidal constituents are indicated in each panel. The blue solid curves are the corresponding solutions obtained from the one-dimensional linear model of Prandle and Rahman (1980).

Last but not least, the phase lag between high water and high-water slack, $\varepsilon$, provides a strong indication of the occurrence of tidal reflection. As shown in the right panel of Figure $3, \varepsilon$ almost vanishes at the inner continental shelf. This means that the tidal motion is progressive co-oscillating. When the tide penetrates the estuary, $\varepsilon$ experiences a sudden increase of $\pi / 4$ because of friction (Friedrichs and Madsen, 1992). The phase lag decreases further upstream, and becomes practically zero at $\mathrm{km} 80$. This behavior indicates that in the upper third of the estuary, the tidal propagation is partially standing due to the wave reflection on the head dam. Notice that other estuaries may also exhibit a $90^{\circ}$ phase difference between currents, $u$, and elevations, $\eta$, at strongly convergent stretches, despite the fact that $u$ and $\eta$ appear individually progressive (Friedrichs and Aubrey, 1994). However, this is not the case of the Guadalquivir estuary, which is weakly convergent, since sections and widths show a mild decrease upstream. 


\section{ANALYSIS OF THE TIDAL REFLECTION}

The tidal reflection at the head dam has consequences not only on wave propagation but also on the bed morphology. With a view to characterizing the potential impact on the morphodynamics, by means of the complex reflection coefficient $R$ and the net mass transport velocity $u_{L}$ close to the bed for each constituent, a deeper analysis of the reflection was carried out. A method that uses a least squares fitting technique (Baquerizo, 1995) in a similar fashion than Mansard and Funke (1980), was used to separate the incident and reflected wave trains and to compute the frequency-dependent complex reflection coefficient. The method requires the use of sea water elevations simultaneously from three tidal gauges. Two additional assumptions have to be adopted a) the tidal wave reflects normally on the reflector (the dam in this case); and b) reflection is dominant over convergence and friction in the stretch of analysis. Condition a) is apparently fulfilled, as the satellital image from Google Earth (Figure 2 , right panel) may indicate. Assumption $b$ ) is fulfilled as long as the stretch under consideration is short enough and close enough to the reflector. In this case, the distance between the three tidal gauges (namely, $\beta_{7}, \beta_{8}$, and $\beta_{9}$ ) is $15 \mathrm{~km}$, which is much shorter than the estuary length or any of the wavelengths of the tidal harmonics analyzed. Therefore, this technique seems to be appropriate to obtain a rough estimation the reflection coefficient. A more accurate value would require to account for the longitudinal and temporal variations of the wetted cross-section, and different wave numbers for the incident and reflected waves (Valle-Levinson, 2010).

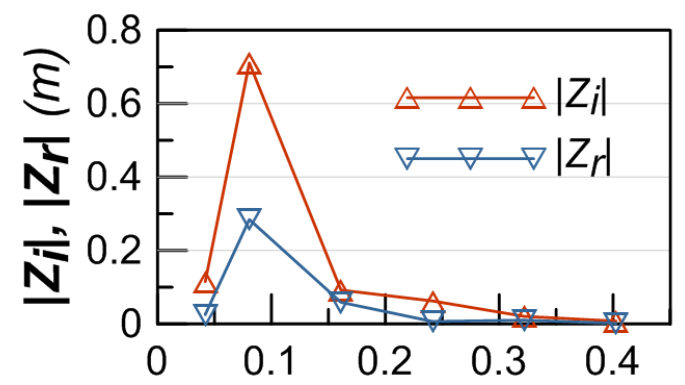

Frequency (hours-1)

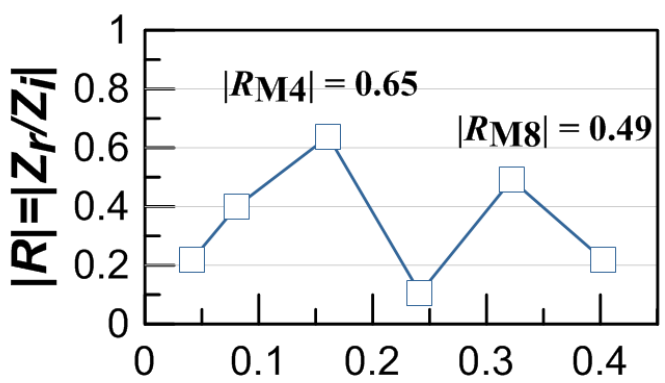

Frequency (hours-1)

Figure 5. Left panel: Magnitude of the complex amplitude of the incident and reflected wave elevations, $Z_{i}$ and $Z_{r}$, respectively. Right panel: Magnitude of the complex reflection coefficient $R$. Values for all the shown magnitudes are listed in Table 1.

Table 1. Complex amplitudes $\left(Z_{i}\right.$ and $\left.Z_{r}\right)$ and phases $\left(\Phi_{i}\right.$ and $\left.\Phi_{r}\right)$ of the incident $\left({ }_{i}{ }_{i}\right)$ and reflected $\left(*_{r}\right)$ wave elevations for each frequency $f$. Amplitudes and phases are expressed, respectively, in meters and degrees Greenwich. The magnitude of the complex reflection coefficient is $|R|$ and the phase difference between incident and reflected waves is denoted as $\Delta \Phi$.

\begin{tabular}{|c|c|c|c|c|c|c|c|}
\hline & $f\left(h^{-1}\right)$ & $\left|Z_{i}\right|(m)$ & $\Phi_{i}\left(^{\mathbf{o}}\right)$ & $\left|Z_{r}\right|(m)$ & $\Phi_{r}\left(^{\mathbf{o}}\right)$ & $\Delta \Phi\left(^{\mathbf{o}}\right)$ & $|R|$ \\
\hline K1 & 0.0418 & 0.1150 & 127.526 & 0.0253 & 91.622 & -35.904 & 0.2200 \\
M2 & 0.0805 & 0.7109 & 176.418 & 0.2844 & -177.786 & 5.796 & 0.4001 \\
M4 & 0.1610 & 0.0921 & -88.783 & 0.0588 & -51.945 & 36.838 & 0.6384 \\
M6 & 0.2415 & 0.0625 & -93.933 & 0.0066 & -37.406 & 56.527 & 0.1056 \\
M8 & 0.3220 & 0.0205 & -10.515 & 0.0101 & 27.408 & 37.923 & 0.4927 \\
M10 & 0.4026 & 0.0077 & 25.029 & 0.0017 & 91.022 & 65.993 & 0.2208 \\
\hline
\end{tabular}

Figure 5 (right panel) shows the results of the magnitude of $R$, computed from the complex amplitudes of the incident and reflected wave elevations (see also Table 1), for the diurnal, semidiurnal, and overtides. The reflection coefficient varies significantly with the frequency. This behavior has also been found in the propagation of gravity waves in dissipative and reflecting systems, such as 
beaches and porous media (Wright and Short, 1983; Tatavarti et al., 1988; Losada et al., 1993; Baquerizo et al., 1997, 1998). Relatively low values are obtained for diurnal and semidiurnal constituents, namely, $|R| \approx 0.22$ and $|R| \approx 0.40$, respectively (Table 1 ). The magnitude of the reflection coefficient attains its maximum at quarter-diurnal frequencies $(|R| \approx 0.63$ for the M4 overtide). The lowest magnitude for $R$ is obtained for the sixth-diurnal frequencies $(|R| \approx 0.10)$. The eighth-diurnal overtide (M8) exhibits a local maximum, whose value is $|R| \approx 0.49$. From this figures it can be concluded that tidal reflection in the dam has a relevant influence on the dynamics of the upper part of the estuary.
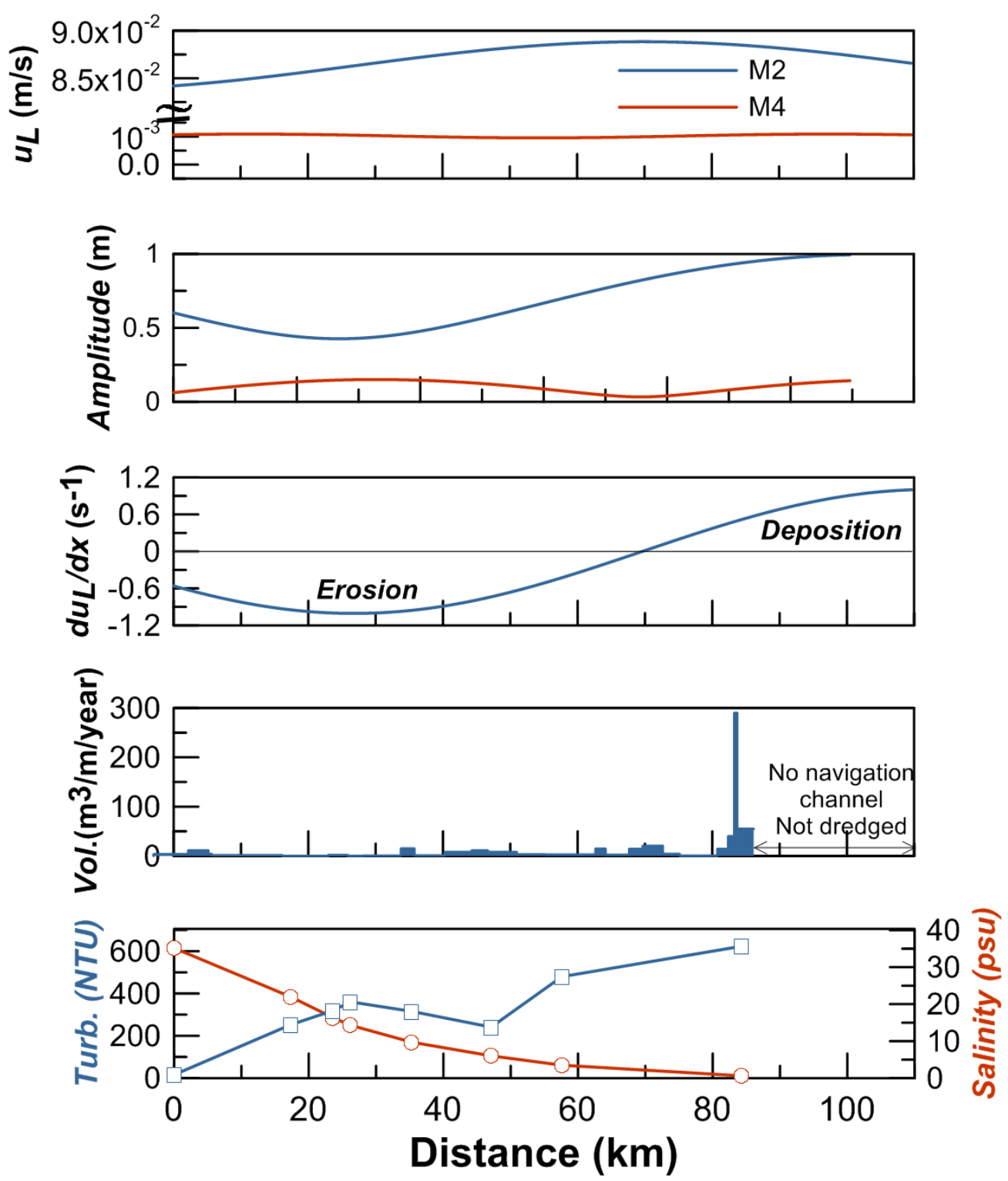

Figure 6. From top to bottom. a) Mass transport velocity for constituents M2 (blue) and M4 (red); b) Amplitude for constituents M2 (blue) and M4 (red); c) Longitudinal gradient of the mass transport velocity for the M2 constituent; d) Mean annual dredged volume in $\mathrm{m}^{3} / \mathrm{m} / \mathrm{yr}$ (historic data from 1964 to 1998 , provided by the Port Authority of Seville); e) Depth and tidally-averaged turbidity, expressed in Nepherometric Turbidity Units (blue squares, left y-axis), and depth and tidally-averaged Salinity, expressed in Practical Salinity Units (red circles, right y-axis). 
The tidal reflection generates residual currents that may have consequences in the bed morphology. Following Carter et al. (1973) and Baquerizo et al. (1998), the net mass transport velocity in the bottom boundary layer, $u_{L}$, associated with the partially standing motion was also obtained (Figure 6). This Lagrangian velocity is induced by the oscillatory motion of the tides, and was computed assuming a non-viscous and irrotational flow. At order $\mathrm{O}\left(\omega k A^{2}\right), u_{L}$ is composed of the Eulerian velocity and the Stokes drift, with $\omega$ is the angular frequency, $k$ is the wave number, and $A(\omega)$ is the relevant wave amplitude scale. Although the boundary layer generated by the tidal flow occupies the whole water column, the mass transport velocity is calculated at a vertical location where the shear stresses are highest. This occurs near the bottom, at a distance from the bed of, approximately, one width of the laminar boundary layer, whose value is approximately $8-20 \mathrm{~cm}$ for the main tidal components.

Figure 6 (first panel) shows the mass transport velocity for the M2, the most energetic constituent, and M4, the constituent which exhibits the larger reflection coefficient. The magnitude of $u_{L}$ for M2 is on the order of $9 \mathrm{~cm} / \mathrm{s}$, comparable to other residual currents, e.g. the gravitational circulation associated with the along-channel density gradient. Its value is almost 80 times greater than those obtained for the M4, despite the larger reflection coefficient. Notice that the ratio between mass transport velocities for M2 and M4 is, approx., a factor 10 larger than the ratio between their respective tidal amplitudes (Figure 6, second panel). The effect of the M2 constituent is thus dominant and would explain by itself the deposition patterns. Figure 6, third panel, shows the along-channel gradient of $u_{L}$

for M2, which gives a clue of the potential bed patterns associated with tidal reflection. The areas where deposition or erosion is favored are indicated. As can be observed in the figure, the reflection of the M2 component favors sedimentation in a reach near the head dam, prolonging its influence to the vicinity of the Port of Seville. It is precisely there where the Port Authority dredges with greater frequency (Figure 6 , fourth panel). Since the sediment load is found to vary as a positive power of the current velocity, the sediment load transport associated to the tidal motion is expected to be zero at the dam. This implies that the maximum deposition should appear at a distance away but not far from the dam. A sediment bar may thus develop, which should be detectable by a bathymetric mapping of the bed. This morphological pattern can be modified by other residual currents, e.g. those associated with the river contribution, possibly displacing the position of the bar. The bed pattern from $\mathrm{km} 70$ to the mouth shown in Figure 6, third panel, should be regarded as indicative, since the reflection coefficients entirely lose their validity away from the dam.

The tidal wave reflection is expected to play a significant role in other relevant processes. The Guadalquivir estuary is one of the most turbid estuaries in the world (Ruiz and Losada, 2010), and, due to the importance of turbidity in the socio-economic activities in the estuary, a reasonable and significant question is to what extent the tidal reflection influences the spatio-temporal turbidity distribution. Figure 6, fifth panel, shows the depth and tidally-averaged salinity during a mean-tide cycle. As expected for a positive estuary, the salinity monotonically decreases from the mouth to the head dam (Díez-Minguito et al., 2012b). On the contrary, the turbidity is relative low at the inner shelf and increases gradually upstream. It shows two maxima. The first one, at $\mathrm{km} 25$ approx. from the mouth, is probably due to the secondary circulation induced by two consecutive bends, which have the smallest curvature radius of the whole estuary. Secondary circulation, which typically increases as the ratio of the radius of bend curvature to channel width decreases, apparently enhances in this stretch the mixing of the cross-section (Valle-Levinson, 2010). The absolute maximum was observed in $\mathrm{km} \mathrm{84,}$ near the Port of Seville. In this stretch, the morphodynamical effects of the tidal reflection at the head dam are felt. However, besides reflection, other mechanisms are present. Under low-riverflow conditions, the position of the null-point of the salinity intrusion, which is known to generate the classical estuarine turbidity maximum, is also located around $\mathrm{km} 80$. Further analysis and details on the relative influence of these mechanisms on turbidity will be published elsewhere.

\section{CONCLUSIONS}

Prominent reflected waves in estuaries are uncommon. However, the inner end of short- and intermediate-length tidal channels may have a major impact on the tide propagation through a significant fraction of the estuary (Bowers and Lennon, 1990; Blanton et al., 2002; Elias et al. 2003; 
Díez-Minguito et al., 2012a; Dou et al., 2012). The effect of a barrier, or a closure dam, or a sluice at the head of a tidal channel manifests itself away from them via a reflected wave.

This is the case of the Guadalquivir estuary. Analysis of data measured by an extensive monitoring network revealed the occurrence of tidal reflection at the Alcalá del Río head dam. This result is supported, among other evidences shown and discussed in this work, by the partially standing tidal motion along the upper third of the estuary. Reflection is a frequency-dependent transformation, and so it becomes apparent in the estimated complex reflection coefficients at the head dam. The reflection coefficients of the most significant constituents were calculated, based on water level data. The solution was obtained by assuming that incident and reflected wave transformations due to friction and the convergence of the channel are negligible in comparison to reflection. The magnitude of the frequency dependent reflection coefficient attains its maximum at quarter-diurnal constituents. A secondary peak was obtained at eighth-diurnal overtides. In spite of that, erosion-deposition patterns induced by the tidal reflection are mainly due to the M2, the most energetic tidal constituent. This semidiurnal constituent favors sedimentation near the head dam. Sedimentation extends to the entrance of the Port of Seville, where precisely intense dredging works have took place in the last fifty years.

\section{ACKNOWLEDGMENTS}

This work was funded by the Department of Innovation, Science and Business of the Andalusian Regional Government (Projects P09-TEP-4630 and P10-RNM-6352) and the research contract "Propuesta metodológica para diagnosticar y pronosticar las consecuencias de las actuaciones humanas en el estuario del Guadalquivir" between the University of Granada and Consejo Superior de Investigaciones Científicas (CSIC), under the direction of the Port Authority of Seville. I.P. was supported by the Spanish Ministry of Economy and Competitiveness (former Spanish Ministry of Science and Innovation) under Proyect BES-2010-032333.

\section{REFERENCES}

Álvarez, O., B. Tejedor, and J. Vidal. 2001. La dinámica de marea en el estuario del Guadalquivir: un caso peculiar de 'resonancia antrópica', Física de la Tierra, 13, 11-24.

Baquerizo, A. 1995. Wave Reflection on Beaches: Methods of Assessment and Forecasting, Ph.D. Thesis, University of Cantabria. In Spanish.

Baquerizo, A., M. A. Losada, J. Smith, and N. Kobayashi. 1997. Crossshore variation of wave reflection from beaches. Journal of Waterways, Port, Coastal, and Ocean Engineering, 123, 274.

Baquerizo, A., M.Á. Losada, and J.M. Smith. 1998. Wave reflection from beaches: A predictive model, Journal of Coastal Research, 14(1), 291-298.

Blanton, J. O., G. Lin, and S. A. Elston. 2002. Tidal current asymmetry in shallow estuaries and tidal creeks. Continental Shelf Research, 22, 1731-1743.

Bowers, D. G., and G. W. Lennon. 1990. Tidal progression in a near-resonant system--A case study from South Australia. Estuarine, Coastal and Shelf Science, 30(1), 17-34.

Carter, T.G., P. L. F. Liu, and C. C. Mei. 1973. Mass transport by waves and offshore sand bedforms. Journal of the Waterways, Harbors and Coastal Engineering Division, 99(2), 165-184.

Díez-Minguito, M., A. Baquerizo, M. Ortega-Sánchez, G. Navarro, and M.Á. Losada. 2012. Tide transformation in the Guadalquivir estuary (SW Spain) and process-based zonation. Journal of Geophysical Research, 117, C3, C03019.

Díez-Minguito, M., E. Contreras, M. J. Polo, and M.Á. Losada. 2012. Spatio-temporal distribution, long-channel fluxes, and post-riverflood recovery of salinity in the Guadalquivir estuary (SW Spain). Submitted to the Journal of Geophysical Research.

Dou, X., X. Zhang, X. Wang, and X. Zhao. 2012. Numerical simulation study on deposition downstream estuarine sluice. Proceedings of $33^{\text {rd }}$ International Conference on Coastal Engineering, ASCE. Santander. In press.

Dyer, K. R. 1997. Estuaries: A Physical Introduction. $2^{\text {nd }}$ Edition. John Wiley \& Sons Ltd. Chichester, $U K$.

Elias, E., M. Stive, H. Bonekamp, and J. Cleveringa. 2003. Tidal inlet dynamics in response to human intervention, Coastal Engineering Journal, 45(4), 629-658.

Friedrichs, C. T., and D. G. Aubrey. 1994. Tidal propagation in strongly convergent channels, Journal of Geophysical Research, 99(C2), 3321-3336. 
Friedrichs, C. T., and O. S. Madsen. 1992. Nonlinear diffusion of the tidal signal in frictionally dominated embayments, Journal of Geophysical Research, 97, 5637-5650.

Hansen, D., and M. Rattray Jr, 1965. Gravitational circulation in straits and estuaries, Journal of Marine Research, 23(2), 104-122.

Losada, I., M. A. Losada, and A. Baquerizo. 1993. An analytical method to evaluate the efficiency of porous screens as wave dampers. Applied Ocean Research, 15(4), 207-215.

Mansard, E.P.D., and E.R. Funke. 1980. The measurement of incident and reflected spectra using a least squares method, Proceedings of the 17th International Conference on Coastal Engineering, ASCE, 2, 154-172.

Navarro, G., F.J. Gutierrez, M. Díez-Minguito, M.Á. Losada, and J. Ruiz. 2011. Temporal and spatial variability in the Guadalquivir estuary: A challenge for real-time telemetry, Ocean Dynamics, 61(6), 753-765.

Navarro, G., I.E. Huertas, E. Costas, S. Flecha, M. Díez-Minguito, I. Caballero, V. López-Rodas, L. Prieto, J. Ruiz. 2012. Use of a Real-Time Remote Monitoring Network (RTRM) to Characterize the Guadalquivir Estuary (Spain), Sensors, 12(2), 1398-1421.

Prandle, D., and M. Rahman. 1980. Tidal response in estuaries. Journal of Physical Oceanography, 10, $1552-1573$.

Ruiz, J., and M. Á. Losada. (2010). Propuesta metodológica para diagnosticar y pronosticar las consecuencias de las actuaciones humanas en el estuario del Guadalquivir (in Spanish). Technical Report, Chapter 7.

Tatavarti, R., D. Huntley, and A. Bowen. 1988. Incoming and outgoing wave interactions on beaches. Coastal Engineering, ASCE, pp. 136-150.

Valle-Levinson, A. (Ed.) 2010. Contemporary Issues in Estuarine Physics. Cambridge University Press, $U K$.

Wang, Z.B., and M. Fernández-Bermejo. 2010. Impact of fluvial sediment input to tidal amplification in an estuary. EGU General Assembly 2010, 12, 4868.

Wright, L., and A. Short. 1983. Morphodynamics of beaches and surf zones in Australia. Handbook of Coastal Processes and Erosion, CRC Press, pp. 35-64. 